\title{
TOXICIDADE ORAL DE NANOPARTÍCULAS DE PRATA: UMA REVISÃO DE LITERATURA ${ }^{1}$
}

\author{
ORAL TOXICITY OF SILVER NANOPARTICLES: A LITERATURE REVIEW
}

\author{
Carolina Bordin Davidson ${ }^{2}$, Maria Luiza Machado Teixeira ${ }^{2}$, \\ Michele Rorato Sagrillo ${ }^{3}$, William Leonardo da Silva ${ }^{3}$ e Patrícia Gomes ${ }^{3}$
}

\section{RESUMO}

As nanopartículas de prata (AgNPs) estão presentes em produtos comerciais, como pesticidas destinados à agricultura, e possuem uma importante atividade antimicrobiana, acarretando uma relevante exposição aos seres humanos, animais e ao meio ambiente no geral. Dessa forma, é preciso conhecer e avaliar os riscos para a saúde que a exposição às AgNPs pode ocasionar, com destaque ao trato gastrointestinal, em razão da via oral ser uma das principais vias de contato com as nanopartículas, podendo ocorrer a absorção dessas partículas do trato gastrointestinal para os sistemas linfáticos e para a circulação sanguínea. O objetivo deste trabalho foi realizar uma revisão bibliográfica exploratória e qualitativa acerca da toxicidade gastrointestinal in vitro e in vivo de AgNPs. Os resultados encontrados sugerem que a toxicidade das AgNPs está atribuída principalmente ao tamanho, revestimento e tempo de exposição. Sendo assim, é importante levar em consideração as propriedades e características físico-químicas das AgNPs, bem como o destino no trato gastrointestinal, para que se possa avaliar de forma segura e precisa os riscos das AgNPs para a saúde humana e dos animais.

Palavras-chave: Toxicidade gastrointestinal, Nanoprata, Nanotecnologia.

\section{ABSTRACT}

Silver nanoparticles (AgNPs) are present in commercial products, such as pesticides, and have an important antimicrobial activity, resulting in an important exposure to humans, animals, and the environment in general. Thus, it is necessary to know and assess the health risks that exposure to AgNPs can lead, especially to the gastrointestinal tract, because the oral route is one of the main routes of contact with nanoparticles, and absorption of these particles from the gastrointestinal tract to the lymphatic systems and blood circulation. The aim of this work was to conduct an exploratory and qualitative literature review on the in vitro and in vivo gastrointestinal toxicity of AgNPs. The results found suggest that the toxicity of AgNPs is mainly attributed to size, coating, and exposure time. Therefore, it is important to consider the properties and physicochemical characteristics of AgNPs, as well as their fate in the gastrointestinal tract, so that the risks of AgNPs for human and animal health can be safely and accurately evaluated.

Keywords: Gastrointestinal toxicity, Nanosilver, Nanotechnology.

1 Trabalho realizado no Programa de Pós-Graduação em Nanociências - Universidade Franciscana (UFN).

2 Estudantes de mestrado do Programa de Pós-Graduação em Nanociências - Universidade Franciscana (UFN). Email: carolina.davidson@ufn.edu.br, maria.lmteixeira@ufn.edu.br

3 Colaboradores. Professores do Programa de Pós-Graduação em Nanociências - Universidade Franciscana (UFN).

E-mail: sagrillomr@ufn.edu.br,w.silva@ufn.edu.br, patriciagomes@ufn.edu.br 


\section{INTRODUÇÃO}

A nanotecnologia proporciona características físico-químicas especiais aos nanomateriais e nanopartículas (NPs) (ADAMS; BARBANTE, 2013). Em exemplo, à medida que a escala de tamanho das partículas diminui, os efeitos sobre a área de superfície tornam-se extremamente importantes, pois ocorrem efeitos quânticos que levam a mudanças nas propriedades desses materiais (BHUSHAN, 2017). Dessa forma, as nanopartículas possuem pelo menos uma dimensão com cerca de 1 a $100 \mathrm{~nm}$, elevada área superficial e consequente aumento da porcentagem de átomos na superfície, conferindo elevada reatividade, sendo uma das características mais importantes para as aplicações biológicas e no meio ambiente (ADAMS; BARBANTE, 2013; LIU; WORKALEMAHU; JIANG, 2017). Atualmente, as nanopartículas metálicas têm atraído atenção na pesquisa científica devido sua aplicabilidade em diferentes áreas, como engenharia, medicina, química e física (DOS SANTOS et al., 2014), podendo ser utilizada como agentes antibacterianos, em produtos industriais, domésticos, sensores ópticos e produtos relacionados à saúde, como em revestimentos de dispositivos médicos, cosméticos e como agentes anticâncer (ZHANG et al., 2016).

Assim como toda a tecnologia, as nanopartículas e materiais nanoestruturados também precisam passar por avaliações de sustentabilidade e de risco para a saúde de animais e seres humanos e para o meio ambiente (KRUG; WICK, 2011). Vários métodos têm sido adotados para a síntese dessas nanopartículas. Os métodos físicos e químicos convencionais podem ser muito caros e perigosos, desta forma, os métodos biológicos parecem ter abordagens simples, rápidas, atóxicas, que podem produzir nanopartículas que cumpram com os requisitos necessários para sua utilização (ZHANG et al., 2016).

As nanopartículas de prata (AgNPs) podem ser sintetizadas de forma biogênica por meio de bactérias, fungos, extratos de plantas, flores, folhas e frutos e enzimas (SOLOMON et al., 2007). O tamanho, morfologia e estabilidade das nanopartículas dependem do método de preparação, natureza do solvente, concentração, força do agente redutor e da temperatura utilizada na síntese das nanopartículas (JAMKHANDE et al., 2019). As plantas contêm carboidratos, gorduras, proteínas e vários tipos de metabólitos secundários que atuam como agentes redutores para produzir nanopartículas a partir de sais metálicos sem que ocorra a produção de subprodutos tóxicos (SIDDIQI; HUSEN; RAO, 2018). Portanto, a nanotecnologia oferece novas aplicações, permitindo melhorias e a produção de uma ampla gama de NPs de diferentes tipos e propriedades (DONALDSON et al., 2004; NI; SHI; WANG, 2018).

A toxicidade das nanopartículas, ou nanotoxicologia, ocorre por dois fatores que as tornam interessantes, únicas e importantes, que atuam em conjunto: a grande área superficial e a reatividade ou a toxicidade intrínseca da superfície dessas nanopartículas (DONALDSON et al., 2004; OBERDÖRSTER; OBERDÖRSTER; OBERDÖRSTER, 2005). Assim, para que haja um desenvolvimento seguro e sustentável de nanopartículas, a nanotoxicologia abrange o estudo dos determinantes físico-químicos, vias de exposição, biodistribuição, parâmetros moleculares, cito e genotoxicidade e aspec- 
tos regulatórios (ARORA; RAJWADE; PAKNIKAR, 2012). Estudos mostram que AgNPs podem ser tóxicas para podem ser tóxicas para células do fígado e cérebro de ratos, que devido à sua espessura fina, podendo romper a membranas das células e causar morte celular nesses tecidos (TRIPATHI et al., 2017). A ingestão de AgNPs pode ocorrer de diversas formas, como por meio de alimentos e embalagens alimentares (GAILLET; ROUANET, 2015). Estudos mostram que pode ocorrer a absorção dessas partículas do trato gastrointestinal para os sistemas linfáticos e para a circulação sanguínea (SAMBALE et al., 2015).

A figura 1 representa esquematicamente as áreas de interesse de avaliação da toxicidade das nanopartículas.

Figura 1 - Conjunto de parâmetros que envolvem a toxicidade de NPs.

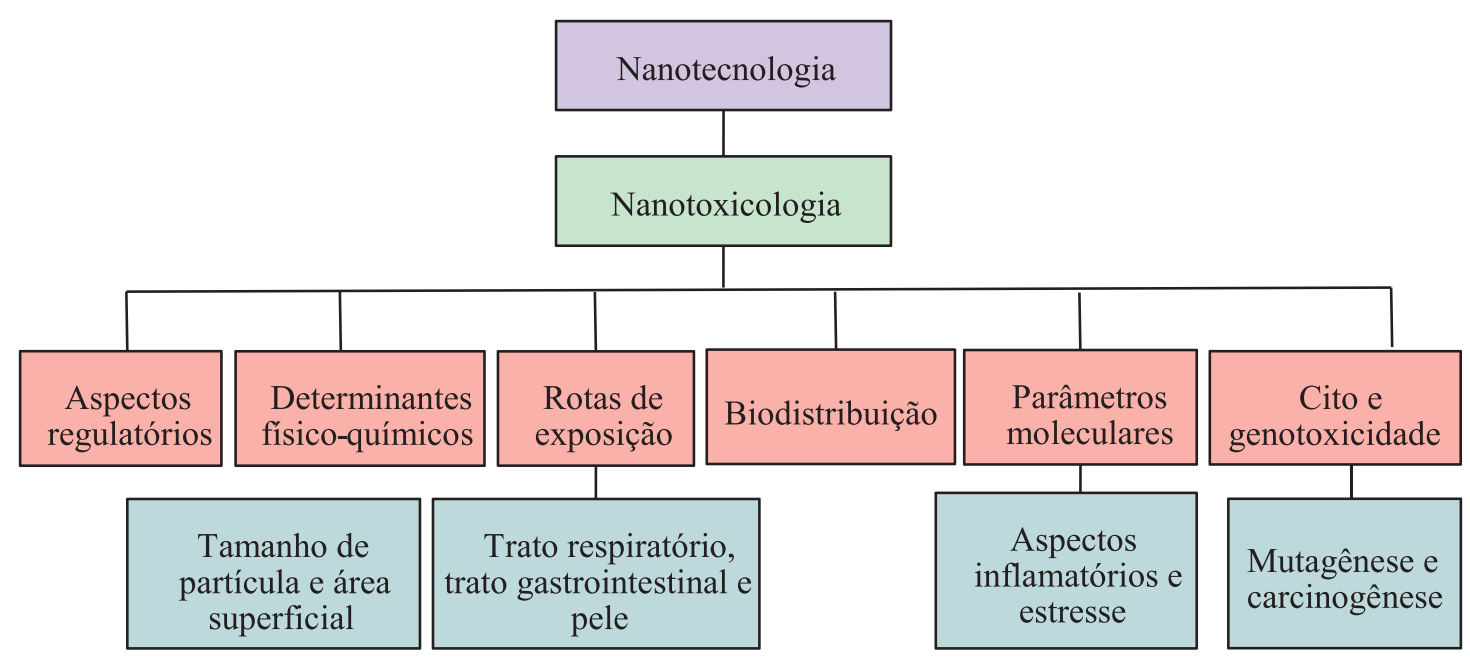

Fonte: Construção dos autores.

Neste contexto, o presente artigo buscou realizar um estudo de revisão qualitativo e exploratório sobre a toxicidade de AgNPs, pois, a utilização desses compostos tanto para fins comerciais, quanto para fins biomédicos, requer o desenvolvimento de mais investigações acerca dos benefícios e efeitos nocivos causados por essas nanopartículas.

\section{MÉTODOS}

O presente estudo foi definido como uma revisão bibliográfica exploratória e qualitativa. A busca dos artigos foi baseada nos seguintes descritores: gastrointestinal AND toxicity AND silver nanoparticles; nanosilvers AND intestine e toxicity AND gastrointestinal AND nanosilvers. A pesquisa ocorreu nas bases de dados eletrônicos PubMed (US National Library of Medicine), Web of Science e ScienceDirect.

Os critérios de inclusão utilizados para selecionar os artigos foram: artigos originais publicados entre 2014 e 2021, escritos na língua inglesa e disponibilizados na íntegra, bem como estudos que 
contemplem modelos in vitro e/ou in vivo. Os artigos de revisão, publicados em outro idioma senão a língua inglesa e repetidos foram excluídos.

Após a busca nas bases de dados com os descritores selecionados, os artigos foram selecionados para leitura na íntegra de acordo com os critérios de inclusão. A busca resultou em 241 artigos no total, dos quais 27 preencheram os critérios de inclusão e foram selecionados para compor esse estudo.

\section{RESULTADOS E DISCUSSÃO}

As AgNPS são amplamente utilizadas em produtos comerciais, como antibióticos, produtos de limpeza e produtos destinados à agricultura. A via oral é uma das principais vias de contato com essas NPs e, por esse motivo, é importante compreender os processos físicos e químicos que levam às alterações das NPs ao longo do trato digestivo (ABDELKHALIQ et al., 2020). As NPs administradas via oral ultrapassam a barreira gastrointestinal, podendo atingir o sistema circulatório, ser distribuídas no organismo e, eventualmente, causar efeitos adversos à saúde (BÖHMERT et al., 2014).

Estudos in vitro utilizando como modelo de estudo apenas a linhagem celular imortalizada de células de adenocarcinoma colorretal humano (Caco-2), mostraram que ocorreu redução da viabilidade celular, produção de espécies reativas de oxigênio (EROS) e desregulação de proteínas. As alterações dependem da concentração utilizada, podendo variar de $0,7 \mu \mathrm{g} / \mathrm{mL}$ até $10 \mu \mathrm{g} / \mathrm{mL}$, como mostra a tabela 1.

Tabela 1 - Resultados de citotoxicidade de nanopartículas de prata em cultura celular de Caco-2.

\begin{tabular}{|c|c|c|}
\hline AUTORES & $\begin{array}{c}\text { MODELO DE } \\
\text { ESTUDO }\end{array}$ & RESULTADOS \\
\hline $\begin{array}{c}\text { CHEN } \\
\text { et al., } 2016\end{array}$ & Caco-2 & $\begin{array}{l}\text { Em } 24 \mathrm{~h} \text { de exposição, } 0,7 \mu \mathrm{g} / \mathrm{mL} \text { das AgNPs com revestimento de citrato, } 0,9 \mu \mathrm{g} / \mathrm{mL} \text { das AgNPs } \\
\text { sem revestimento e } 1 \mu \mathrm{g} / \mathrm{mL} \text { das AgNPs com revestimento de polivinilpirrolidona (PVP) indu- } \\
\text { ziram a diminuição na viabilidade celular das células intestinais. A exposição de curto prazo e } \\
\text { doses maiores induziu EROs, dano em mitocôndrias e membrana celular, apoptose e inflamação, } \\
\text { com níveis maiores de interleucina-8 (IL-8). }\end{array}$ \\
\hline $\begin{array}{l}\text { BÖHMERT } \\
\text { et al., } 2014\end{array}$ & Caco-2 & $\begin{array}{l}\text { Os resultados sugerem que as AgNPs podem superar a ação dos fluidos gastrointestinais sem } \\
\text { formar grandes quantidades de agregados, indicando que as AgNPs podem atingir as células } \\
\text { epiteliais intestinais, após a ingestão, com uma pequena redução no seu potencial citotóxico, } \\
\text { devido à baixa formação de agregados e consequente reduzida liberação de íons } \mathrm{Ag}^{+} \text {. }\end{array}$ \\
\hline $\begin{array}{l}\text { GIORIA } \\
\text { et al., } 2018\end{array}$ & Caco-2 & $\begin{array}{l}\text { Aproximadamente } 1 \% \text { da quantidade inicial de AgNPs exposta às células foi internalizada à } \\
\text { membrana das células em } 10 \mu \mathrm{g} / \mathrm{mL} \text { por } 72 \mathrm{~h} \text {. As AgNPs de } 30 \mathrm{~nm} \text { revestidas com citrato } \\
\text { desencadearam uma desregulação de várias proteínas do citoesqueleto. Segundo os autores, a } \\
\text { concentração mais alta de AgNPs causou mais desregulação de proteínas. }\end{array}$ \\
\hline
\end{tabular}


Chen e colaboradores (2016) compararam a toxicidade de AgNPs com diferentes revestimentos (sem revestimento, citrato e PVP), medindo cerca de 20 a $30 \mathrm{~nm}$, a curto e longo prazo de exposição (1 a 21 dias), em células Caco-2. Tanto a curto quanto a longo prazo, foi verificado que o tipo de revestimento afeta o nível de toxicidade das AgNPs, sendo o revestimento com citrato o mais citotóxico, acarretando inibição do crescimento celular e morte. Em 24 horas de exposição, verificou-se que $0,7 \mu \mathrm{g} / \mathrm{mL}$ das nanopartículas de prata com revestimento de citrato, $0,9 \mu \mathrm{g} / \mathrm{mL}$ das AgNPs sem revestimento e $1 \mu \mathrm{g} / \mathrm{mL}$ das AgNPs com revestimento de PVP induziram a diminuição na viabilidade celular das células intestinais. A exposição de curto prazo e doses mais altas induziu a EROs, ocasionando dano mitocondrial na membrana celular, apoptose e inflamação, com altos níveis de IL-8. Embora, apenas a inibição da proliferação celular tenha sido o efeito observado na exposição a longo prazo, a concentração de $0,3 \mu \mathrm{g} / \mathrm{mL}$, que foi considerada atóxica para as células intestinais, induzindo a ativação inflamatória nas células. Após 21 dias de exposição às nanopartículas de prata com o revestimento de citrato em uma concentração de $0,4 \mu \mathrm{g} / \mathrm{mL}$, a viabilidade celular diminuiu para menos de 50\%, enquanto as células expostas às AgNPs com o revestimento de PVP permaneceram com a viabilidade normalizada. Similarmente, Böhmert e colaboradores (2014) caracterizaram físico-químicamente as AgNPS ao longo da digestão artificial a fim de simular os processos bioquímicos que ocorrem durante o processo digestivo, através de um modelo in vitro com células Caco-2. Utilizando fracionamento de fluxo de campo, espalhamento de luz dinâmico e espalhamento de raios-X a baixo ângulo, demonstraram que as partículas agregam parcialmente, como resultado do processo do digestivo. Entretanto, no ambiente fortemente ácido ( $\mathrm{pH}$ 2) do estômago observou-se um aumento do tamanho das partículas (de 14 para 99 nm) quando comparado com meios com pH mais básico, atribuindo a mudanças conformacionais dos agentes estabilizadores e/ou à adsorção de proteínas. Em relação à citotoxicidade, os resultados sugerem que as AgNPs podem superar a ação dos fluidos gastrointestinais sem formar grandes quantidades de agregados, indicando que as NPs podem atingir as células epiteliais intestinais, após a ingestão, com uma pequena redução no seu potencial citotóxico, devido à baixa formação de agregados e consequente reduzida liberação de íons $\mathrm{Ag}^{+}$.

Gioria e colaboradores (2018), realizaram uma análise proteômica comparativa de células Caco2, usadas como modelo in vitro do intestino delgado, essas células foram expostas a AgNPs de $30 \mathrm{~nm}$ estabilizadas com citrato realizando a análise em dois momentos, após 24 horas e 72 horas. A síntese dos AgNPs ocorreu por meio da redução do $\mathrm{AgNO}_{3}$ com citrato e ácido tânico. Os autores selecionaram duas doses para a análise proteômica, utilizando uma concentração não tóxica de $1 \mu \mathrm{g} / \mathrm{mL}$ e uma alta concentração de $10 \mu \mathrm{g} / \mathrm{mL}$. Em seus resultados, os autores observaram que aproximadamente apenas $1 \%$ da quantidade inicial de AgNPs exposta às células foi internalizada à membrana das células na concentração mais elevada $(10 \mu \mathrm{g} / \mathrm{mL})$ e tempo de exposição (72 horas). Foi possível observar a formação de proteínas desreguladas, esse efeito foi causado mais por AgNPs do que pelos íons de prata livres liberados na solução pelas NPs, essas proteínas foram classificadas por meio de funções biológicas, 
uma fração considerável das proteínas identificadas como desreguladas estava relacionada à energia e metabolismo, síntese ou estabilidade/transcrição de proteínas, morfologia celular e transporte, bem como resposta ao estresse. As AgNPs de $30 \mathrm{~nm}$ revestidas com citrato desencadearam uma desregulação de várias proteínas do citoesqueleto, como, por exemplo, Tubulina beta-4B (TUBB4), um dos principais constituintes dos microtúbulos; A subunidade 5 do complexo da proteína $2 / 3$ relacionada à actina (ARPC5), que funciona como um componente do complexo Arp2/3 e está envolvida na regulação da polimerização da actina. O tratamento com $10 \mu \mathrm{g} / \mathrm{mL}$ de AgNPs por 72 horas também ocasionou uma desregulação significativa da glutationa sintetase (GSS), esta proteína está envolvida na resposta inflamatória e na neutralização do estresse oxidativo. Como mecanismo de defesa contra a lesão causada, as células expressaram níveis alterados de glutaredoxina-3 (GLRX3) e peroxirredoxina-1 (PRDX1) quando expostas a $10 \mu \mathrm{g} / \mathrm{mL}$ de AgNPs por 72 horas. Segundo os autores, a concentração mais alta de AgNPs causou mais desregulação de proteínas.

Em estudos in vitro que utilizaram culturas de células Caco-2 em associação com outros tipos celulares intestinais e hepáticas, também foi observado redução da viabilidade celular, aumento na produção de citocinas pró-inflamatórias em ambos os tipos celulares utilizados nos estudos, e dependendo da concentração das AgNPs os autores observaram a presença de células necróticas e micronúcleos, como mostra a tabela 2.

Tabela 2 - Estudos in vitro utilizando co-culturas para visualizar toxicidade das nanopartículas de prata.

AUTORES

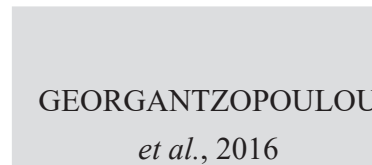

et al., 2016

Caco-2/TC7:HT29-MTX

GILLOIS

et al., 2021

Caco-2/HT29-MTX

VAN DER ZANDE

et al., 2016

MARTIROSYAN,

BAZES e

SCHNEIDER, 2014

SAHU et al., 2014

MODELO DE ESTUDO
A camada de muco impactou na modulação da citotoxicidade promovida pelas nanopartículas, ocorrendo maior proteção com partículas maiores, levando à $\downarrow$ dos efeitos citotóxicos, proteção contra geração de EROs, $\downarrow$ da liberação de IL-8 e menos alterações proteômicas, quando comparado com partículas menores $(20 \mathrm{~nm})$ e $\mathrm{AgNO}_{3}$. Uma perda significativa da viabilidade celular foi obtida após 7 dias de exposição, independentemente do modelo de célula para MesosilverTM e AgNPs de concentrações de $3 \mu \mathrm{g} / \mathrm{mL}$. Para a co-cultura Caco-2/HT29-MTX, a perda na atividade metabólica ocorreu a partir de $1 \mu \mathrm{g} / \mathrm{mL}$, independentemente do produto contendo prata coloidal. A absorção de Ag pareceu $\uparrow$ com o $\uparrow$ do tamanho de NP em ambos os tipos de células. A exposição a AgNPs induziu a expressão diferencial de vários genes em células Caco-2 e MCF-7. Os autores concluíram que em ambas as células Caco-2 e MCF-7, $\mathrm{AgNO}_{3}$ e as exposições à AgNP causaram fortes respostas ao estresse. As AgNPs foram citotóxicas em $40 \mu \mathrm{g} / \mathrm{mL}^{-1}$, e induziram ao estresse oxidativo a partir da concentração de $45 \mu \mathrm{g} / \mathrm{mL}^{-1}$ após 3 horas de incubação. Os ensaios de imunofluorescência demonstraram que as nanopartículas de prata afetam as distribuições de ocludina e outras proteínas, sugerindo a abertura das junções oclusivas na barreira epitelial. Dependendo da concentração da nanopartícula ocorreu um $\uparrow$ da população de micronúcleos contendo células, células apoptóticas/necróticas, também foram encontradas células hipodiploides, porém, estas foram observadas em células HepG2, mas não em células Caco-2. 
Georgantzopoulou e colaboradores (2016) avaliaram os efeitos das nanopartículas de prata e nitrato de prata $\left(\mathrm{AgNO}_{3}\right)$ em um modelo de co-cultivo de células intestinais (Caco-2/TC7:HT29-MTX) com secreção de muco, constituindo uma barreira mecânica protetora contra agentes exógenos e pode influenciar na absorção de partículas. Os resultados demonstraram que a camada de muco impactou na modulação da citotoxicidade promovida pelas nanopartículas, dependente do tamanho, ou seja, há maior proteção com partículas maiores $(200 \mathrm{~nm})$, levando à diminuição dos efeitos citotóxicos, proteção contra geração de EROs, diminuição da liberação de IL-8 e menos alterações proteômicas, quando comparado com partículas menores $(20 \mathrm{~nm})$ e $\mathrm{AgNO}_{3}$. As mudanças observadas a nível proteômico e os níveis aumentados de IL-8 indicam que as AgNPs desencadeiam uma resposta patogênica e interferem na regulação de proteínas responsáveis pela manutenção da função e pela integridade da barreira intestinal, o que não se pode associar apenas aos efeitos da prata pura, pois tanto as NPs de $20 \mathrm{~nm}$ quanto $200 \mathrm{~nm}$ foram absorvidas pelas células e as NPs de $20 \mathrm{~nm}$ foram localizados principalmente em organelas com alto teor de enxofre e fósforo. Gillois e colaboradores (2021) realizaram um estudo utilizando o mesmo modelo do estudo anterior, com objetivo de avaliar e comparar a toxicidade de dois produtos comerciais de prata disponíveis em dois modelos epiteliais intestinais humanos. A exposição repetida foi realizada para determinar a viabilidade celular ao longo de 18 dias de diferenciação celular em placas de 24 poços. Os autores utilizaram concentrações de $0,1,1$ e $3 \mu \mathrm{g} / \mathrm{mL}$. A genotoxicidade foi determinada em células Caco-2 em proliferação por imunofluorescência $\gamma \mathrm{H} 2 \mathrm{AX}$. Primeiro foi avaliado o efeito de concentrações de 0-12 $\mu \mathrm{g} / \mathrm{mL}$ das suspensões Mesosilver ${ }^{\mathrm{TM}}$ e $\operatorname{AgNPs}$ na viabilidade celular em monoculturas Caco-2 e co-culturas Caco2/HT29-MTX durante 18 dias de exposição repetida. Segundo os autores, ambos induziram uma perda na viabilidade celular, conforme medido usando o ensaio AlamarBlue ${ }^{\circledR}$, considerando a concentração, tempo, modelo de célula e forma dependente do produto de prata coloidal. Após 2 dias de exposição, a viabilidade celular gradual e significativamente diminuiu para Mesosilver ${ }^{\mathrm{TM}}$ e AgNPs em concentrações de $6 \mu \mathrm{g} / \mathrm{mL}$ em monocultura e co-cultura de células modelos. Os primeiros sinais de perda de viabilidade celular foram observados a $3 \mu \mathrm{g} / \mathrm{mL}$ de AgNPs para células Caco-2. Uma perda significativa da viabilidade celular foi obtida após 7 dias de exposição, independentemente do modelo de célula para Mesosilver ${ }^{\mathrm{TM}} \mathrm{e}$ AgNPs de concentrações de $3 \mu \mathrm{g} / \mathrm{mL}$. A viabilidade celular usando o ensaio AlamarBlue ${ }^{\circledR}$ foi medida para a monocultura Caco-2, onde houve uma diminuição significativa e marcada na viabilidade celular a $3 \mu \mathrm{g} / \mathrm{mL}$ Mesosilver TM, e de $1 \mu \mathrm{g} / \mathrm{mL}$ de AgNPs. Para a co-cultura Caco-2/HT29-MTX, a perda na atividade metabólica ocorreu a partir de $1 \mu \mathrm{g} / \mathrm{mL}$, independentemente do produto contendo prata coloidal. Ainda segundo os autores, estes resultados implicam que a prata presente nos produtos Mesosilver ${ }^{\mathrm{TM}}$ e AgNPs foi internalizada e capaz de cruzar a barreira epitelial do células Caco-2 e Caco-2/HT29-MTX, embora não tenha sido possível determinar de que forma (AgNPs e/ou prata iônica). A presença de quebras de fita dupla de DNA foi examinada em células Caco-2 em proliferação expostas por 1, 6 ou 24 horas em concentrações de $0,1,1$ e $3 \mu \mathrm{g} / \mathrm{mL}$ para avaliar se Mesosilver ${ }^{\mathrm{TM}} \mathrm{e}$ 
AgNPs são potenciais agentes genotóxicos. Nenhum efeito genotóxico ocorreu após o tratamento com produto de prata coloidal a $0,1 \mu \mathrm{g} / \mathrm{mL}$ ou 1 hora de tratamento. No entanto, $\gamma \mathrm{H} 2 \mathrm{AX}$ demonstrou aumento significativo na intensidade após 6 horas de exposição ao Mesosilver ${ }^{\mathrm{TM}}$ ou AgNPs a $1 \mu \mathrm{g} / \mathrm{mL}$.

Van Der Zande et al. (2016), realizaram um estudo com objetivo de compreender de forma mais profunda as respostas moleculares e celulares em células Caco-2 e MCF-7 após a exposição de AgNP. AgNPs de 20, 30, 60 e $110 \mathrm{~nm}$ e $\mathrm{AgNO}_{3}$ foram expostos por 6 e 24 horas. Após 24 horas de exposição, células Caco-2 exibiram citotoxicidade leve, no entanto, ainda se considera este um valor aceitável de viabilidade subtóxica, exceto para AgNPs de $110 \mathrm{~nm}$, que mostraram uma viabilidade inferior de $\sim 70 \%$ a $25 \mu \mathrm{g} / \mathrm{mL}$. Em células MCF-7 a citotoxicidade estava completamente ausente. A absorção de prata pareceu aumentar com o aumento do tamanho de NPs em ambos os tipos de células, aumentos significativos foram observados entre AgNPs de $20 \mathrm{~nm}$ e AgNPs de $110 \mathrm{~nm}$ e entre AgNPs de $60 \mathrm{~nm}$ e AgNPs de $110 \mathrm{~nm}$ em células MCF-7 após 24 horas de exposição, e em células Caco-2 entre AgNPs de 20 nm e AgNPs de 110 nm após 6 horas de exposição. Nas células Caco-2 e MCF-7, a captação de $\mathrm{AgNO}_{3}$ foi maior após 24 horas do que após 6 horas, com exceção de AgNPs de $110 \mathrm{~nm}$, a captação de AgNPs não aumentou entre 6 e 24 horas de exposição. A microscopia confocal (CM) mostrou claramente a presença de AgNPs de $60 \mathrm{~nm}$ e AgNPs de $110 \mathrm{~nm}$ em vários planos dentro das células após 6 horas de exposição, com co-localização parcial com lisossomos em ambos os tipos de células. AgNPs não foram detectados no núcleo. A exposição a AgNPs, bem como a $\mathrm{AgNO}_{3}$, induziu a expressão diferencial de vários genes em células Caco-2 e MCF-7. A maioria dos DEGs (Genes expressos significativamente diferencialmente) foram regulados positivamente do que regulados negativamente em ambos os tipos de células, exceto para as células Caco-2 tratadas com AgNPs de $110 \mathrm{~nm}$, resultando em um alto número de genes regulados negativamente. A análise da via biológica dos perfis de expressão gênica em células Caco-2 expostas a AgNPs de $110 \mathrm{~nm}$ indicou regulação negativa do ciclo celular e regulação negativa das vias metabólicas e de biossíntese, indicando fortes efeitos citotóxicos. Após 6 e 24 horas de exposição, 90 e 73 genes, respectivamente, foram regulados positivamente por todas as $\mathrm{NPs} \mathrm{AgNO}_{3}$ em células Caco-2. Após 6 horas, nenhum dos genes foi afetado exclusivamente por todos os NPs, mas após 24 horas havia 130 genes regulados positivamente afetados exclusivamente por todos os NPs. As células MCF-7 mostraram uma sobreposição de 34 genes expressos entre todos os NPs e $\mathrm{AgNO}_{3}$ após 6 e 24 horas de exposição. Os autores concluíram que em ambas as células Caco-2 e MCF-7, $\mathrm{AgNO}_{3}$ e as exposições às AgNPs causaram fortes respostas ao estresse.

Martirosyan, Bazes e Schneider (2014) avaliaram a toxicidade aguda de AgNPs, em relação a formação de íons $\mathrm{Ag}^{+}$e o estresse oxidativo, de forma isolada e coadministrada com compostos fenólicos presentes na matriz alimentícia em um modelo in vitro de células do trato gastrointestinal (Caco-2 e RajiB). As NPs possuíam cerca de $20 \mathrm{~nm}$ e foram utilizadas em concentrações de 15 a $90 \mu \mathrm{g} / \mathrm{mL}$ nas células. As AgNPs foram citotóxicas para as células Caco-2 em uma concentração de $40 \mu \mathrm{g} / \mathrm{mL}$ e 
induziram ao estresse oxidativo a partir da concentração de $45 \mu \mathrm{g} / \mathrm{mL}$ após 3 horas de incubação, sendo a principal causa atribuída à toxicidade aguda neste estudo. A ruptura da integridade da barreira epitelial pelas nanopartículas de prata em monoculturas e co-culturas de células Caco-2 foi estabelecida pela diminuição da resistência elétrica transepitelial e o aumento da incorporação de Lucifer Yellow, um corante fluorescente. Os ensaios de imunofluorescência demonstraram que as AgNPs afetam as distribuições de ocludina e outras proteínas, sugerindo a abertura das junções oclusivas na barreira epitelial. Em outro estudo, utilizando concentrações menores, Sahu e colaboradores (2014) utilizaram células Hep-G2 de fígado humano e células Caco-2, realizando as análises por meio de citometria de fluxo. As AgNPs foram caracterizadas pela técnica de espalhamento de luz dinâmico (DLS), microscopia eletrônica de transmissão (TEM) e em análise de espectrometria de massas com fonte de plasma indutivamente acoplado (ICP-MS). As células foram expostas a nanoprata em concentrações de 1,0 a $15,0 \mu \mathrm{g} / \mathrm{mL}$. As células fixadas foram tratadas continuamente por 48 horas a $37^{\circ} \mathrm{C}$ em uma atmosfera saturada úmida de $5 \%$ de $\mathrm{CO}_{2}$ no ar. As células foram tratadas continuamente por 4 horas a $37{ }^{\circ} \mathrm{C}$ em uma saturação umidificada em atmosfera de $5 \%$ de $\mathrm{CO}_{2}$ no ar. Em seu estudo, os autores concluíram que as AgNPs de 20 nm é citotóxica para Hep-G2 e Caco-2 dependente da concentração. Os autores observaram que dependendo da concentração das NPs ocorreu um aumento da população de micronúcleos contendo células, células apoptóticas/necróticas, também foram encontradas células hipodiploides, porém, estas foram observadas em células Hep-G2, mas não em células Caco-2.

Nos estudos in vivo, de maneira geral, todos encontraram alterações na microflora intestinal dos animais tratados com AgNPs em diferentes concentrações. Com exceção de Hendrickson e colaboradores (2016), todos os demais artigos trouxeram relatos de efeitos citotóxicos causados por AgNPs, como destacado na tabela 3.

Tabela 3 - Resultados in vivo utilizando ratos e camundongos como modelo de estudo para os testes de toxicidade de nanopartículas de prata.

\begin{tabular}{|c|c|c|}
\hline AUTORES & $\begin{array}{l}\text { MODELO DE } \\
\text { ESTUDO }\end{array}$ & RESULTADOS \\
\hline $\begin{array}{l}\text { JAVUREK } \\
\text { et al., } 2017\end{array}$ & Ratos machos & Redução da microbiota intestinal. \\
\hline $\begin{array}{l}\text { HENDRICKSON } \\
\text { et al., } 2016\end{array}$ & Ratos machos & $\begin{array}{l}\text { Exposições únicas e múltiplas resultaram em acúmulo de prata no fígado e rins principalmente, } \\
\text { seguido de acúmulo no baço, estômago e intestino delgado. Os autores concluíram que as AgNPs } \\
\text { são capazes de ser absorvidas do trato gastrointestinal para a corrente sanguínea e se acumular nos } \\
\text { órgãos secundários de ratos, entretanto não apresentaram efeitos tóxicos pronunciados em condi- } \\
\text { ções experimentais agudas ou subagudas. }\end{array}$ \\
\hline ORR et al., 2019 & Ratos & $\begin{array}{l}\text { Interação da prata com o trato gastrointestinal pode iniciar um processo inflamatório que pode levar } \\
\text { a alterações na permeabilidade gastrointestinal e/ou deficiência de nutrientes de forma sexoespecífica. }\end{array}$ \\
\hline $\begin{array}{l}\text { BERGIN } \\
\text { et al., } 2016\end{array}$ & Ratos & $\begin{array}{l}\text { A maior parte da prata foi detectada nas fezes, porém também foi realizada a análise da detecção } \\
\text { de prata em } 48 \mathrm{~h} \text { no trato gastrointestinal (esôfago, estômago, intestino delgado, ceco, intestino } \\
\text { grosso), fígado, baço e rim. Destes órgãos, a maior parte da prata foi detectada no trato gastroin- } \\
\text { testinal, particularmente o ceco e cólon. }\end{array}$ \\
\hline
\end{tabular}




\begin{tabular}{|c|c|c|}
\hline $\begin{array}{l}\text { BOLANDI } \\
\text { et al., } 2021\end{array}$ & Ratos & $\begin{array}{l}\text { AgNPs melhoraram a microflora gastrointestinal, porém, também apresenta um efeito potencial } \\
\text { no aparelho digestivo, podendo afetar a biodiversidade e função microbiana. }\end{array}$ \\
\hline $\begin{array}{l}\text { WILLIAMS } \\
\text { et al., } 2015\end{array}$ & Ratos & $\begin{array}{l}\text { Em ratos machos, somente a nano de } 110 \mathrm{~nm} \text { mostrou atividade antibacteriana. Em ratos fêmeas, } \\
\text { as NPs de } 10 \mathrm{~nm} \text { mostraram elevada atividade antibacteriana para todas as doses administradas } \\
\text { por gavagem. A maioria dos animais tratados com } 200 \mathrm{mg} / \mathrm{kg} \text { de peso corporal de acetato de } \\
\text { prata (AgOAC) teve gastroenterite grave. Os resultados do estudo mostraram que o tratamento } \\
\text { com nanopartículas demonstrou estimular a } \downarrow \text { da expressão de genes envolvidos na regulação de } \\
\text { células T, especialmente em doses baixas e médias. }\end{array}$ \\
\hline YUN et al., 2015 & Ratos & $\begin{array}{l}\text { As concentrações de prata no sangue do grupo de tratamento } \uparrow \text { significativamente em comparação } \\
\text { ao grupo de controle. Além disso, a concentração de prata nos órgãos apresentou } \uparrow \text { em todas as } \\
\text { doses dos grupos tratados. A detecção de prata foi detectada em maiores concentrações nas fezes. }\end{array}$ \\
\hline $\begin{array}{l}\text { WILDING } \\
\text { et al., } 2016\end{array}$ & Camundongos & $\begin{array}{l}\text { Os autores concluíram que as AgNPs ingeridas de tamanho e revestimento variados, administradas } \\
\text { em doses repetidas equivalentes a } 2.000 \mathrm{x} \text { a dose oral de referência para prata e } \sim 100-400 \mathrm{x} \text { as con- } \\
\text { centrações com atividade antimicrobiana in vitro, não causaram alterações na associação, estrutura } \\
\text { ou diversidade do microbioma intestinal em camundongos avaliado por meio de pirosequenciamento. }\end{array}$ \\
\hline
\end{tabular}

Javurek e colaboradores (2017) investigaram se AgNPs seriam capazes de alterar a microbiota intestinal, devido a ação antimicrobiana já conhecida, em ratos machos durante duas semanas de exposição. As AgNPs possuíam cerca de $50 \mathrm{~nm}$ e foram dissolvidas no bebedouro dos animais, em uma concentração de 3,6 mg/Kg. Como resultado, os grupos tratados tiveram reduções da microbiota intestinal (Clostridium spp., Bacteroides uniformis, Christensenellaceae, Coprococcus eutactus, Oscillospira spp., Dehalobacterium spp., Peptococcaeceae, Corynebacterium spp., Aggregatibacter pneumotropica) em relação ao grupo controle. Similarmente, Hendrickson e colaboradores (2016) descreveram a biodistribuição e a ação biológica de AgNPs em experimentos de toxicidade aguda (única exposição e dose de $2000 \mathrm{mg} / \mathrm{Kg}$ ) e subaguda (múltiplas exposições durante 30 dias e dose de $250 \mathrm{mg} / \mathrm{Kg}$ ). As NPs administradas não eram revestidas e mediam cerca de $12 \mathrm{~nm}$, sendo administradas por gavagem (via intragástrica) em ratos machos. Foi demonstrado que as exposições únicas e múltiplas resultaram em acúmulo de prata no fígado $(0,87 \pm 0,37 \mu \mathrm{g} / \mathrm{g}$ de órgão) e rins $(0,24 \pm 0,02$ $\mu \mathrm{g} / \mathrm{g}$ de órgão) principalmente, seguido de acúmulo no baço, estômago e intestino delgado. Embora tenha ocorrido acumulação de prata em alguns órgãos, as concentrações detectadas nos tecidos foram menores $(<99 \%)$ do que as doses administradas, indicando excreção eficiente do organismo. De modo geral, as exposições agudas e subagudas não causaram mortalidade animal ou sinais de toxicidade, manifestadas como mudanças na aparência do animal ou desvios comportamentais e na atividade locomotora. A avaliação ex-vivo não revelou anormalidades morfológicas nos órgãos. Os índices hematológicos e os parâmetros bioquímicos dos ratos tratados não diferiram dos animais do grupo controle. Os autores concluíram que as AgNPs são capazes de ser absorvidas do trato gastrointestinal para a corrente sanguínea e se acumular nos órgãos secundários de ratos, entretanto não apresentaram efeitos tóxicos pronunciados em condições experimentais agudas ou subagudas.

No estudo de Orr e colaboradores (2019), ratos machos e fêmeas foram expostos a diferentes tamanhos de nanopartículas de prata $(10$ e $110 \mathrm{~nm})$ através do método de gavagem durante 13 semanas, em doses de 9, 18 e $36 \mathrm{mg} / \mathrm{Kg}$, a fim de verificar se as AgNPs eram capazes de alterar a 
permeabilidade intestinal e a expressão de genes que controlam as junções celulares do epitélio intestinal. Os resultados indicam que as AgNPs, principalmente as que mediam $10 \mathrm{~nm}$, apresentaram efeito sobre as junções celulares que são conhecidas por ditarem a permeabilidade intestinal. A expressão de RNA mensageiro (mRNA) de genes que representam as junções oclusivas, adesão focal, junção aderente e grupos de hemidesmossomos foram regulados positivamente em ratos fêmeas tratadas com AgNPs de $10 \mathrm{~nm}$, enquanto nenhuma alteração ou regulação negativa dos mesmos genes foi detectada em animais machos. Além disso, uma maior concentração de TNF- $\alpha$, foi observada em fêmeas tratadas com AgNPs em comparação com os controles. Os autores propõem que a interação da prata com o trato gastrointestinal pode iniciar um processo inflamatório que pode levar a alterações na permeabilidade gastrointestinal e/ou deficiência de nutrientes de forma sexoespecífica. Complementar a esses resultados, no estudo realizado por Bergin e colaboradores (2016) foi avaliado a ingestão aguda de AgNPs bem caracterizadas de dois tamanhos diferentes $(20$ e $110 \mathrm{~mm}$ ) e com revestimentos (PVP, citrato) utilizando marcadores toxicológicos tradicionais (pesos corporais, pesos de órgãos, efeitos histopatológicos) em modelos de ratos, foram utilizados 384 animais. A maior dose utilizada no estudo foi de $10 \mathrm{mg} / \mathrm{kg}$ peso corporal/dia (pc/d). Segundo os autores, a maior parte da prata foi detectada nas fezes, porém também foi realizada a análise da detecção de prata em 48 horas no trato gastrointestinal (esôfago, estômago, intestino delgado, ceco, intestino grosso), fígado, baço e rim. Destes órgãos, a maior parte da prata foi detectada no trato gastrointestinal, particularmente o ceco e cólon. No entanto, a prata total do trato gastrointestinal em $48 \mathrm{~h}$ representou apenas entre $0,02 \%$ e $0,27 \%$ do montante dosado. A prata em outros órgãos era mínima, no entanto, o cumulativo de recuperação de prata em qualquer tecido testado (trato gastrointestinal, fígado, baço, rim) foi de 50,5\% para todas as AgNPs e para AgOAc às 48 horas. Os autores concluíram que as AgNPs ingeridas são minimamente absorvidas pelo trato intestinal: entre 70\% e $100 \%$ da prata administrada foi recuperada nas fezes por 48 horas após a administração.

Confirmando os resultados anteriores, em que as NPs foram capazes de causar alterações na microflora gastrointestinal dos animais, Bolandi e colaboradores (2021), avaliaram o efeito das AgNPs sobre a microflora intestinal, onde as AgNPs apresentam um efeito potencial no aparelho digestivo podendo afetar a biodiversidade e função microbiana, outros efeitos das AgNPs relacionados aos estados fisiológicos do hospedeiro, como o estado imunológico e fatores de estresse podem ser influenciados negativamente por nanopartículas de prata. Williams e colaboradores (2015), avaliaram mudanças nas populações da microbiota intestinal e expressão gênica da mucosa intestinal em ratos, administrado por meio de gavagem oral AgNPs de 10, 75 e $110 \mathrm{~nm}$ e acetato de prata. Foram administradas doses de AgNPs de 9, 18 e $36 \mathrm{mg} / \mathrm{kg}$ de peso corporal/dia e acetato de prata de 100, $200 \mathrm{e}$ $400 \mathrm{mg} / \mathrm{kg}$ de peso corporal/dia, as doses foram administradas duas vezes ao dia por 13 semanas. Os tecidos ileais de cinco animais de cada grupo foram avaliados com relação ao efeito das AgNPs na microbiota bacteriana associada à mucosa intestinal. Em ratos machos, somente as AgNPs de $110 \mathrm{~nm}$ mostraram atividade antibacteriana. Em ratos fêmeas, as NPs de $10 \mathrm{~nm}$ mostraram elevada atividade 
antibacteriana para todas as doses administradas por gavagem. A maioria dos animais tratados com $200 \mathrm{mg} / \mathrm{kg}$ de peso corporal de AgOAC teve gastroenterite grave. A administração de AgNPs e AgOAC alterou a proporção de Firmicutes e Bacteroidetes, o que segundo os autores, pode ser devido a uma mudança na subpopulação bacteriana. Os animais que receberam AgNPs de $10 \mathrm{~nm}$ e $75 \mathrm{~nm}$ mostraram diminuição da população de Lactobacillus. Ratos machos e fêmeas tratados com NPs de $110 \mathrm{~nm}$ demonstraram maior proporção de Bacteroides. Os resultados do estudo mostraram que o tratamento com NPs demonstrou estimular a diminuição da expressão de genes envolvidos na regulação de células T, especialmente em doses baixas e médias. Segundo os autores, o estudo mostrou que as respostas de expressão gênica observadas são o resultado de interações específicas de NPs e não simplesmente o efeito de íons de prata. Por fim, os autores concluíram que o consumo de AgNPs pode ter impactos sutis na saúde intestinal, incluindo efeitos na microbiota e na função imunológica do hospedeiro. Porém, são necessários mais estudos acerca dessas partículas.

Yun e colaboradores (2015), realizaram um estudo com o objetivo de examinar a toxicidade sistêmica de nanopartículas de dióxido de silício $\left(\mathrm{SiO}_{2}\right)$, prata $(\mathrm{Ag})$ e óxido de ferro $\left(\mathrm{Fe}_{2} \mathrm{O}_{3}\right)$. As nanopartículas foram administradas por via oral em ratos, diariamente durante um período de 13 semanas. A análise hematológica revelou que o nível de leucócitos em fêmeas tratadas com $1.030,5 \mathrm{mg} / \mathrm{kg}$ das AgNPs foi significativamente maior do que no grupo de controle. O nível de plaquetas dos machos tratados com 1.030,5 mg/kg de AgNPs foi significativamente menor do que no grupo controle. Os grupos de nanopartículas de $\mathrm{SiO}_{2}$ e $\mathrm{Fe}_{2} \mathrm{O}_{3}$ não apresentaram alterações hematológicas significativas. A análise da acumulação de Si, Ag e Fe, a toxicidade sistêmica induzida por nanopartículas e as concentrações de $\mathrm{Si}, \mathrm{Ag}$ e Fe foram medidas em amostras de sangue, órgãos, urina e fezes após a administração oral repetida das NPs através da espectrometria de massa por plasma acoplado indutivamente. As concentrações de Ag no sangue do grupo de tratamento aumentaram significativamente em comparação ao grupo de controle. Além disso, a concentração de Ag nos órgãos (fígado, rim, baço, pulmão e cérebro) apresentou aumento em todas as doses dos grupos tratados com a AgNPs. Os dados sobre a excreção das AgNPs foram consistentes com os padrões de absorção e distribuição. A concentração de Ag nas fezes dos grupos de tratamento com nanopartículas de Ag foi significativamente maior do que no grupo de controle. A prata foi detectada em maiores concentrações nas fezes do que na urina ou nos tecidos, sugerindo que a maioria das nanopartículas foi excretada através das fezes.

Em estudo sobre a relação das nanopartículas com a microflora intestinal, de forma mais detalhada, Wilding e colaboradores (2016) realizaram a administração oral por gavagem em camundongos uma vez ao dia durante 28 dias consecutivos, realizando o sacrifício no dia 29. Os efeitos da 
dosagem oral repetida de AgNPs de $110 \mathrm{~nm}$ revestidas com PVP nas comunidades microbianas intestinais foram avaliados considerando que o tamanho relativamente grande e o revestimento estável iriam diminuir a dissolução e a absorção do trato intestinal, deixando assim uma maior proporção do material em contato com micróbios intestinais intraluminais. Nos resultados os autores mostraram que os perfis das comunidades microbianas foram construídos por pirosequenciamento de fragmentos do gene 16S rRNA bacteriano amplificado do DNA da ponta cecal, sendo um total de 9 filos representados nas comunidades microbianas intestinais desses camundongos, mas 97,3\% das sequências presentes em todos os camundongos nos grupos estavam dentro de três filos, Bacteroidetes (54,0\%), Firmicutes (30,9\%), e Deferribacteres (abundância média total de 12,4\%). Não houve diferenças significativas entre os grupos na abundância relativa de qualquer filo. A diversidade da comunidade microbiana dentro de cada grupo, foi semelhante para as AgNPs de $110 \mathrm{~nm}$ revestidas de PVP, AgOAc e grupos de água. Os efeitos das AgNPs de $20 \mathrm{~nm}$ revestidas com PVP, AgNPs de $20 \mathrm{~nm}$ recobertas com citrato e AgNPs de $110 \mathrm{~nm}$ revestidas com citrato nas comunidades microbianas intestinais foram avaliados em camundongos alimentados com AgNPs de $20 \mathrm{~nm}$ revestidas de PVP, AgNPs de $20 \mathrm{~nm}$ revestidas de citrato ou AgNPs de $110 \mathrm{~nm}$ revestidas de citrato por 28 dias, em comparação com água. Um grupo de controle positivo adicional para alterações bacterianas foi incluído, os animais receberam cefoperazona na água para beber por 12 dias. Os perfis da comunidade microbiana cecal foram construídos gerando um total de 9 filos representados sendo a maioria (98,9\%) distribuída em três filos Bacteroidetes (56,2\%), Firmicutes (37,7\%), e Deferribacteres (5,04\%). Segundo os autores, apenas os animais tratados com cefoperazona apresentaram diferenças significativas na abundância dos filos, com diminuição acentuada de Bacteroidetes e mudança para predominância de Firmicutes. Os autores concluíram que as AgNPs ingeridas de tamanho e revestimento variados, administradas em doses repetidas equivalentes a 2.000x a dose oral de referência para prata e $\sim 100-400 \mathrm{x}$ as concentrações com atividade antimicrobiana in vitro, não causaram alterações na associação geral da comunidade, estrutura ou diversidade do microbioma intestinal em camundongos avaliado por meio de pirosequenciamento.

Estudos in vivo utilizando peixes e mexilhões como modelo de estudo, demonstraram que em peixes, os tecidos em que foram encontradas maiores concentrações bioacumuladas das AgNPs foram em brânquias e no intestino. Os autores também observaram que os efeitos citotóxicos são maiores quando são utilizadas menores concentrações das nanopartículas, pois, segundo os autores, em maiores concentrações as nanopartículas podem formar agregados, não sendo capazes de desenvolver suas funções. Foram observados diversos efeitos tóxicos a nível celular e tecidual como mostra a tabela 4. 
Tabela 4 - Efeitos citotóxicos de nanopartículas de prata em modelos de peixes e mexilhões.

\begin{tabular}{|c|c|c|}
\hline AUTORES & $\begin{array}{c}\text { MODELO DE } \\
\text { ESTUDO }\end{array}$ & RESULTADOS \\
\hline $\begin{array}{l}\text { PECORARO } \\
\text { et al., } 2017\end{array}$ & Zebrafish & $\begin{array}{l}\text { As AgNPs causaram danos à estrutura das brânquias como edema subepitelial, hiperplasia, } \\
\text { fusão lamelar e teleangectasia. A necrose das vilosidades intestinais com redução de seu com- } \\
\text { primento também foi demonstrada no intestino. O grupo exposto à concentração mais } \uparrow \text { teve } \\
\text { um grau de toxicidade } \downarrow \text { em comparação com o grupo tratado com concentrações } \downarrow \text { de NPs. }\end{array}$ \\
\hline $\begin{array}{l}\text { XIAO et al., } \\
2020\end{array}$ & Zebrafish & $\begin{array}{l}\text { As AgNPs foram absorvidas principalmente via ingestão oral pelos zebrafish e se acumula- } \\
\text { ram principalmente no fígado, intestino e guelras. No intestino, a matéria orgânica natural } \\
\text { inibiu efetivamente as nanopartículas de prata de penetrar nas membranas celulares dos } \\
\text { tecidos internos. }\end{array}$ \\
\hline $\begin{array}{l}\text { KAKAKHEL } \\
\text { et al., } 2021\end{array}$ & C. carpio & $\begin{array}{l}\text { A maior mortalidade foi encontrada na dose mais alta }(0,09 \mathrm{mg} / \mathrm{L}) \text {, sendo observada nos dias } \\
2,6,13 \text { e } 19 \text { do experimento. O resultado da bioacumulação mostrou que ocorreu deposi- } \\
\text { ção principalmente no fígado, seguido pelo intestino, brânquias e músculos. No intestino } \\
\text { ocorreu a absorção de } 299,15 \mathrm{mg} \text { em } 20 \text { dias de exposição. Foram observadas alterações } \\
\text { teciduais, atrofia, encurtamento da lamela secundária, degeneração e necrose causadas por } \\
\text { diferentes concentrações em guelras e intestino. }\end{array}$ \\
\hline $\begin{array}{l}\text { SRINONATE } \\
\text { et al., } 2015\end{array}$ & $\begin{array}{l}\text { Oreochromis } \\
\text { niloticus }\end{array}$ & $\begin{array}{l}\text { Os peixes tratados apresentaram degeneração tubular leve à moderada e presença de gotí- } \\
\text { culas hialinas. As lesões mais graves foram observadas no grupo que foi exposto à concen- } \\
\text { tração de } 100 \text { ppm AgNPs, seguido pelos grupos de } 10 \text { e } 1 \text { ppm. O acúmulo de AgNPs foi } \\
\text { observado na mucosa superfície e no lúmen durante todo o experimento. }\end{array}$ \\
\hline $\begin{array}{l}\text { JIMENO- } \\
\text {-ROMERO } \\
\text { et al., } 2017\end{array}$ & Mexilhões & $\begin{array}{l}\text { Houve acúmulo de prata nas células epiteliais digestivas, estomacais e no lúmen intestinal } \\
\text { após a exposição às AgNPs e à prata pura após } 1 \text { dia. A exposição a longo prazo às AgNPs } \\
\text { induziu à diminuição de células digestivas e da integridade da glândula digestiva, resultando } \\
\text { em atrofia e necrose dos alvéolos digestivos, edema e hiperplasia nas brânquias, vacuoliza- } \\
\text { ção nas células digestivas e infiltração de hemócitos no tecido conjuntivo. }\end{array}$ \\
\hline
\end{tabular}

O estudo de Pecoraro e colaboradores (2017) utilizou peixes, expondo-os a concentrações crescentes $(8,45$ e $70 \mu \mathrm{g} / \mathrm{L})$ de AgNPs de $25 \mathrm{~nm}$ e após tratamento por 30 dias, foram sacrificados para realização das análises. Foi avaliado a bioacumulação de AgNPs usando ICP-MS e alterações histológicas, biomarcadores de dano oxidativo e expressão gênica no intestino, fígado e tecidos branquiais de peixes-zebra tratados com AgNPs. Foram utilizadas três soluções diferentes preparadas diariamente a partir da solução de partículas de estoque, adicionadas à água e sonicadas por 4 ciclos, cada um com duração de 15 min tendo 5 min de intervalo utilizando sonicador com frequência de $40 \mathrm{kHz}$ sob exaustor, a fim de romper agregados. Os animais foram selecionados aleatoriamente. Todos os dias o comportamento dos peixes foi avaliado após $0,3,6$ e 24 horas após a exposição às AgNPs, observando mudança na velocidade de nado, perda de equilíbrio, respiração e qualquer possível comportamento anormal. As AgNPs causaram danos à estrutura das brânquias como edema subepitelial, hiperplasia, fusão lamelar e teleangectasia. A necrose das vilosidades intestinais com redução de seu comprimento também foi demonstrada no intestino. O exame imunohistoquímico evidenciou a presença de metalotioneínas, estas são proteínas induzíveis por substratos na presença de íons metálicos e apresentam uma afinidade muito alta para com eles. O grupo exposto à concentração mais alta teve um grau de toxicidade mais baixo em comparação com o grupo tratado com concentrações mais baixas de NPs. Segundo os autores, esses resultados sugerem que quanto maior a concentração, maior 
a probabilidade de as partículas se agregarem e, aos poucos, seu tamanho aumentar, a capacidade de absorção dos tecidos expostos pode diminuir. Os autores concluíram que AgNPs dispersas em água são capazes de atravessar as barreiras mucosas, produzindo um dano a esses órgãos. O principal dano foi ao epitélio da mucosa das guelras e, em menor grau, ao tecido intestinal, entretanto, esse dano seria reversível, pois não foi encontrado nenhum dano à membrana basal. Em estudo similar, Xiao e colaboradores (2020) investigaram a influência da matéria orgânica natural no destino e nos efeitos das AgNPs no ambiente aquático utilizando zebrafish (Danio rerio). Assim, concluíram que a matéria orgânica natural desempenha um importante papel na cinética de bioacumulação e biodistribuição das AgNPs nos peixes, tendo como resultado que as AgNPs foram absorvidas principalmente via ingestão oral pelos zebrafish e se acumularam majoritariamente no fígado, intestino e guelras. No intestino, a matéria orgânica natural inibiu efetivamente as AgNPs de penetrar nas membranas celulares dos tecidos internos e suprimiu a desintegração e dissolução das AgNPs no fluido gastrintestinal, diminuindo a absorção de prata pelo zebrafish, pois as moléculas da matéria orgânica natural são propensas a serem adsorvidas nas superfícies das NPs, que também acarreta aumento do tamanho das partículas e das cargas negativas. Desse modo, o estudo mostra a importância de incorporar os efeitos da matéria orgânica natural e de outras macromoléculas em modelos preditivos para avaliar com maior precisão a toxicidade e os riscos ecológicos das AgNPs em ambientes aquáticos.

Kakakhel e colaboradores (2021) desenvolveram um estudo utilizando peixes C. carpio, com objetivo de verificar se ocorre indução à toxicidade devido à exposição de longo prazo a altas concentrações de AgNPs. A síntese das AgNPs foi mediada por soro sanguíneo (B-AgNPs). As concentrações de nanopartículas de prata utilizadas foram de 0,03, 0,06 e 0,09 mg/L. Os B-AgNPs obtidos foram aplicados in vitro para análise da mortalidade e toxicidade na fauna de peixes. A maior mortalidade foi encontrada na dose mais alta $(0,09 \mathrm{mg} / \mathrm{L})$, sendo observada nos dias 2, 6, 13 e 19 do experimento. O resultado da bioacumulação de B-AgNPs mostrou que ocorreu bioacumulação principalmente no fígado, seguido pelo intestino, brânquias e músculos. Em todos os órgãos, a bioacumulação de B-AgNPs foi dependente da dose, a maior bioacumulação de B-AgNPs ocorreu na concentração de $0,09 \mathrm{mg} / \mathrm{L}$, enquanto a menor bioacumulação foi observada na concentração de 0,03 mg/L. A maior absorção de B-AgNPs foi observada na concentração de $0,09 \mathrm{mg} / \mathrm{L}$, os níveis mais altos de absorção de B-AgNPs foram observados no fígado e no intestino. No intestino ocorreu a absorção de 299,15 mg de B-AgNPs em 20 dias de exposição. Foram observadas alterações teciduais, atrofia, encurtamento da lamela secundária, degeneração e necrose causadas por diferentes concentrações de B-AgNPs em guelras e intestino. A estrutura do tecido branquial foi danificada levando à atrofia e necrose na concentração de $0,03 \mathrm{mg} / \mathrm{L}$ de AgNPs. Na concentração de $0,09 \mathrm{mg} / \mathrm{L}$ ocorreu redução ou encurtamento da lamela. Os peixes expostos à concentração de $0,03 \mathrm{mg} / \mathrm{L}$ de B-AgNPs mostraram que ocorreu uma pequena diminuição no número de células epiteliais na parte superior das vilosidades intestinais, na concentração de $0,06 \mathrm{mg} / \mathrm{L}$ ocorreu necrose e degeneração das células da mucosa, 
e, por fim, a concentração de $0,09 \mathrm{mg} / \mathrm{L}$ levou à necrose e lise celular no epitélio da mucosa das vilosidades. Os autores concluíram que as B-AgNPs provocaram bioacumulação, levando a alterações histológicas nas brânquias e intestino.

No estudo de Srinonate e colaboradores (2015), foram utilizadas AgNPs nas concentrações de 0, 1, 10 e 100 ppm testadas em Oreochromis niloticus, com objetivo de avaliar mortalidade, sinais clínicos, histopatologia e imunohistoquímica. Não foram observados sinais clínicos em peixes tratados com AgNPs de 1 ppm, porém, os grupos de 10 e 100 ppm mostraram poucas horas após a exposição, angústia respiratória ao nadar até a superfície da água, movimentos rápidos de opérculo e dispneia. No dia 1, ocorreu um aumento significativo na mortalidade do grupo tratado com 100 ppm. Nos dias 2-4 pós-exposição, as brânquias dos grupos 10 e 100 ppm mostraram descamação e palidez. Alguns peixes apresentaram hemorragias no fígado, sendo o grupo tratado com 100 ppm o que apresentou lesões mais graves em comparação com o grupo tratado com 10 ppm. Os peixes tratados apresentaram degeneração tubular leve à moderada e presença de gotículas hialinas. As lesões mais graves foram observadas no grupo de exposição a AgNPs de 100 ppm, seguido pelos grupos de 10 e 1 ppm. No dia 0 após exposição, o acúmulo de AgNPs agregadas de cor castanha-preta foi observado em guelras e lúmen de todos os grupos tratados, especialmente nos grupos de 10 e $100 \mathrm{ppm}$. Nos dias 1-4, foi observado o encurtamento e fixação de lamelas branquiais nos grupos tratados com 10 e 100 ppm com o acúmulo de AgNPs. O acúmulo de AgNPs foi observado na mucosa superfície e no lúmen durante todo o experimento.

Jimeno-Romero et al. (2017) avaliaram a biodisponibilidade e a toxicidade de AgNPs estabilizadas com maltose de diferentes tamanhos (20, 40 e $100 \mathrm{~nm}$ ) em mexilhões a curto (3 dias) e longo (21 dias) prazo. A prata pura não foi letal na dose $50 \mu \mathrm{g}$, mas foi letal em 3 dias na dose de $75 \mu \mathrm{g}$. Houve acúmulo de prata nas células epiteliais digestivas, estomacais e no lúmen intestinal após a exposição às AgNPs e à prata pura após 1 dia. $\mathrm{O}$ acúmulo de prata intralisossomal e a desestabilização da membrana lisossomal foi maior após a exposição a todas as formas de prata (nanoparticulada, pura e $\mathrm{AgNO}_{3}$ ) e mais evidente após a exposição as NPs de $20 \mathrm{~nm}$. A exposição a longo prazo às AgNPs induziu à diminuição de células digestivas e da integridade da glândula digestiva, resultando em atrofia e necrose dos alvéolos digestivos, edema e hiperplasia nas brânquias, vacuolização nas células digestivas e infiltração de hemócitos no tecido conjuntivo. Os autores concluíram que, embora não tenha havido um acúmulo substancial de prata nos órgãos dos mexilhões, os efeitos tóxicos parecem ser maiores quanto menor o tamanho da partícula e associaram aos íons $\mathrm{Ag}^{+}$liberados das NPs.

Em estudos de fluído gástrico simulado (FGS), os resultados também indicaram toxicidade causada por AgNPs, os autores observaram a produção de EROs causando estresse oxidativo, resultando em redução da viabilidade celular, os resultados são apresentados na tabela 5. 
Tabela 5 - Estudos com fluído gástrico simulado para análise de toxicidade gástrica de AgNPs.

\begin{tabular}{ccl}
\hline AUTORES & $\begin{array}{c}\text { MODELO DE } \\
\text { ESTUDO }\end{array}$ & \multicolumn{1}{c}{ RESULTADOS } \\
\hline $\begin{array}{c}\text { LALOUX } \\
\text { et al., } 2020\end{array}$ & FGS & $\begin{array}{l}\text { A presença de uma matriz alimentar padronizada influencia as propriedades das nanopartí- } \\
\text { culas de prata, formando uma coroa em torno das nanopartículas, a diminuição do pH e as } \\
\text { enzimas digestivas induzem a aglomeração das nanopartículas durante a fase gástrica. }\end{array}$ \\
AXSON & FGS & $\begin{array}{l}\text { AgNP de } 20 \mathrm{~nm} \text { sofreram } \uparrow \text { de tamanho quanto mais ácido for o meio, enquanto as na- } \\
\text { nopartículas de } 110 \mathrm{~nm} \uparrow \text { de tamanho apenas nos meios de pH 2 e 3.5. AgNPs de 20 nm } \\
\text { apresentaram maior taxa de dissolução com base na área de superfície, acarretando maior } \\
\text { toxicidade celular e estresse oxidativo do que as partículas de 110 nm. }\end{array}$ \\
\hline
\end{tabular}

Em estudo preliminar de Laloux e colaboradores (2020) um método in vitro foi desenvolvido para acompanhar o destino das AgNPs no trato digestório e verificaram que a presença de uma matriz alimentar padronizada influencia as propriedades das AgNPs, formando uma coroa em torno das NPs. Embora a etapa salivar não afete significativamente as AgNPs, a diminuição do pH e as enzimas digestivas induzem a aglomeração das NPs durante a fase gástrica, enquanto a adição dos fluidos intestinais desintegra esses aglomerados. Assim, as AgNPs podem atingir as células intestinais sob a forma nanométrica, mesmo que a presença de alimentos e fluidos gastrointestinais modifique suas propriedades em comparação com as AgNPs puras. Com o objetivo de avaliar o comportamento das AgNPs em um FGS (solução de (ácido clorídrico $(\mathrm{HCl})$, cloreto de sódio $(\mathrm{NaCl})$ e água ultrapura), o estudo de Axson e colaboradores (2015) utilizou AgNPs com tamanhos de 20 e $110 \mathrm{~nm}$ inicialmente e foram expostas a diferentes níveis de acidez do FGS ( $\mathrm{pH}$ 2, 3.5, 4.5 e 5). Foi observado que as NPs de $20 \mathrm{~nm}$ sofreram aumento de tamanho quanto mais ácido for o meio, enquanto as NPs de $110 \mathrm{~nm}$ aumentaram de tamanho apenas nos meios de $\mathrm{pH} 2$ e 3.5. Os autores acreditam que esse comportamento pode ser explicado pela geração de íons $\mathrm{Ag}^{+}$em ambientes ácidos, que precipita com íons $\mathrm{Cl}^{-}$, levando ao crescimento das partículas e facilitando a agregação ao diminuir a repulsão eletrostática em solução. Além disso, partículas de $20 \mathrm{~nm}$ apresentaram maior taxa de dissolução com base na área de superfície, acarretando maior toxicidade celular e estresse oxidativo do que as partículas de 110 nm. De modo geral, os resultados destacam a importância do conhecimento do tamanho inicial, propriedades físico-químicas e cinética das AgNPs após a ingestão para avaliar a toxicidade potencial, visto que ao decorrer do trato gastrointestinal existe variação da acidez ou alcalinidade, que conferem um dos principais pontos de toxicidade às AgNPs após a ingestão via oral.

Nos estudos ex vivo, os resultados se mostram divergentes, existem relatos de alterações no tecido intestinal depois de tratamento com AgNPs, porém no estudo de Pind'áková e colaboradores (2017) ocorreu agregação das NPs no intestino, impedindo que desenvolvessem seus efeitos. Dessa forma, os autores concluíram que não foram observados efeitos citotóxicos relevantes, como mostra a tabela 6 . 
Tabela 6 - Resultados ex vivo dos efeitos de AgNPs.

\begin{tabular}{|c|c|c|}
\hline AUTORES & $\begin{array}{l}\text { MODELO DE } \\
\text { ESTUDO }\end{array}$ & RESULTADOS \\
\hline $\begin{array}{l}\text { GOKULAN } \\
\text { et al., } 2020 .\end{array}$ & $\begin{array}{l}\text { Tecido ileal } \\
\text { humano }\end{array}$ & $\begin{array}{l}\text { As amostras ileais apresentavam importantes marcas de tecido intestinal humano normal, } \\
\text { com presença de muitas bactérias no tecido, as imagens de microscopia eletrônica de trans- } \\
\text { missão dos explantes mostram que as nanopartículas de } 110 \mathrm{~nm} \text { estavam presentes dentro } \\
\text { da mucosa ileal. Segundo os autores, no geral, as amostras masculinas pareciam ser mais } \\
\text { afetadas pela exposição as AgNPs do que as amostras femininas. }\end{array}$ \\
\hline $\begin{array}{l}\text { PIND’ÁKOVÁ } \\
\text { et al., } 2017 .\end{array}$ & $\begin{array}{c}\text { Tecido humano } \\
\text { de boca, gengiva } \\
\text { e intestino }\end{array}$ & $\begin{array}{l}\text { A presença de saliva artificial induziu o aumento das nanopartículas que na presença do fluido } \\
\text { gástrico agregaram-se. Não foram observados efeitos tóxicos e inflamatórios relevantes. }\end{array}$ \\
\hline
\end{tabular}

Gokulan e colaboradores (2020) desenvolveram um estudo com o objetivo de avaliar o uso de um modelo de tecido ileal humano ex vivo para examinar os efeitos dependentes do sexo de AgNP no trato gastrointestinal humano. No estudo, os explantes de tecido foram tratados com AgNPs esféricas $(10 \mathrm{~nm}, 20 \mathrm{~nm}, 75 \mathrm{~nm}$ e $110 \mathrm{~nm})$ a uma concentração de $20 \mu \mathrm{g} / \mathrm{mL}$ por 2 e 24 horas. As amostras foram analisadas usando microscopia eletrônica de varredura (MEV) e microscopia eletrônica de transmissão (MET), cujo objetivo de análise foi duplo, para avaliar a integridade estrutural da amostra de tecido como parte da avaliação geral do modelo de explante (pré-tratamento) e para confirmar a penetração de NPs no tecido (pós-tratamento). A análise através de MEV para avaliar a morfologia, aparência e integridade estrutural do modelo de biópsia ileal mostrou que as amostras ileais utilizadas neste estudo apresentavam importantes marcas de tecido intestinal humano normal, com presença de muitas bactérias no tecido. Na análise de MET das seções ileais antes do tratamento com NPs mostram a morfologia intacta da seção ressecada da mucosa ileal que foi evidenciada pelas microvilosidades intactas e arquitetura subjacente da mucosa ileal, mostrando junções estreitas (zona oclusiva), junções intermediárias (zona aderida ou aderida junções) e desmossomos. Após a incubação com AgNPs de $110 \mathrm{~nm}$, as imagens de MET dos explantes mostram que as NPs estavam presentes dentro da mucosa ileal. A expressão de citocinas foi analisada por gênero para avaliar as respostas dependentes do sexo ao tratamento com AgNPs. A análise emparelhada revelou que o fator estimulador de colônias de granulócitos e macrófagos (GM-CSF) foi significativamente aumentado em amostras retiradas de indivíduos do sexo masculino que foram tratados com AgNPs de $10 \mathrm{~nm}$ e $20 \mathrm{~nm}$ por 2 horas em comparação com controles não tratados. Nenhuma mudança significativa foi observada em amostras retiradas de mulheres tempo de 2 horas. No entanto, no tempo de 24 horas, as amostras femininas mostraram diminuições significativas em interferon-gama (IFN-r) e fator de

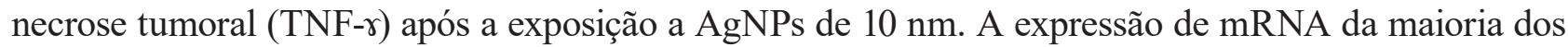
genes de junção celular foi alterada em resposta à exposição de AgNPs no tempo de 24 horas. Os efeitos diferenciais dependentes do tamanho de AgNPs em amostras masculinas e femininas foram observados para genes relacionados à permeabilidade epitelial. AgNPs de menor tamanho $(10 \mathrm{~nm})$ perturbaram mais genes na mucosa ileal masculina do que nas mulheres. No entanto, essa tendência foi 
revertida durante a exposição a AgNPs ou AgOAC de $20 \mathrm{~nm}$, revelando um número maior de genes regulados positivamente em amostras femininas em comparação com amostras masculinas. Segundo os autores, no geral, as amostras masculinas pareciam ser mais afetadas pela exposição às AgNPs do que as amostras femininas.

Por fim, no estudo de Pind'áková et al. (2017) foi determinado o comportamento das AgNPs, a toxicidade e a capacidade de induzir a reações inflamatórias utilizando modelos de tecido humano de boca, gengiva e intestino, também expuseram a diferentes fluidos e enzimas. De acordo com o método de DLS, as NPs apresentaram, inicialmente, $57 \pm 2 \mathrm{~nm}$ de tamanho. A presença de saliva artificial (pH 6.8) induziu o aumento das NPs para $248 \pm 8 \mathrm{~nm}$ dentro do intervalo de 180 minutos de contato com o meio. Na presença do fluido gástrico ( $\mathrm{pH}$ 1.2) as NPs se agregaram imediatamente e passaram a medir $240 \mathrm{~nm}$. Além disso, o tamanho da partícula aumentou para $907 \mathrm{~nm}$ após estarem em contato com o fluido gástrico por um período de 180 minutos. Na presença dos fluidos intestinais (pH 6.8) as NPs também aumentaram de tamanho, para $108 \pm 3 \mathrm{~nm}$. Em contrapartida, não foram observados efeitos tóxicos e inflamatórios relevantes.

\section{CONCLUSÃO}

O presente trabalho realizado permitiu uma melhor compreensão acerca da aplicabilidade das AgNPs, também sobre a toxicidade causada por essas NPs. O aumento da utilização de AgNPs é evidente em várias áreas, dessa forma, é de extrema importância a realização de mais estudos com objetivo de elucidar os possíveis riscos que o uso dessas NPs pode causar tanto aos seres vivos quanto ao meio ambiente.

Em geral, o que define os parâmetros de toxicidade das AgNPs são o tamanho da partícula, tipo de revestimento, forma de administração e tempo de exposição. Entretanto, diversos estudos atribuem a toxicidade da prata pura e das AgNPs aos íons $\mathrm{Ag}^{+}$. De acordo com os estudos avaliados para compor esse trabalho, as AgNPs em baixas concentrações, não produzem uma toxicidade, porém uma exposição excessiva pode levar a bioacumulação de nanopartículas de prata no organismo. As AgNPs são absorvidas no trato gastrointestinal, podendo melhorar a microflora gastrointestinal, mas também apresentam um efeito potencial afetando a biodiversidade e função microbiana. Também podemos observar que dependendo da concentração ou dose administrada essas partículas podem causar a desregulação de proteínas. Em relação à excreção, a detecção de prata foi encontrada em maiores concentrações nas fezes do que em outros fluídos e/ou tecidos, sugerindo assim, que a maior parte das NPs é excretada através das fezes. Por fim, concluímos que é importante avaliar e estudar o destino das AgNPs tanto em modelos in vitro quanto in vivo, analisando como essas NPs se comportam sob ação a diferentes fluídos e as variações de pH presentes no processo de digestão, em relação à absorção, agregação, acumulação nos órgãos, biodisponibilidade, entre outras questões que possam afetar o comportamento das NPs. 


\section{REFERÊNCIAS}

ABDELKHALIQ, A. et al. Impact of in vitro digestion on gastrointestinal fate and uptake of silver nanoparticles with different surface modifications. Nanotoxicology, v. 14, n. 1, p. 111- 126, 2020.

ADAMS, F. C.; BARBANTE, C. Nanoscience, nanotechnology and spectrometry. Spectrochimica Acta Part B, v. 86, p. 3-13, 2013.

ARORA, S.; RAJWADE, J. M.; PAKNIKAR, K. M. Nanotoxicology and in vitro studies: The need of the hour. Toxicology and Applied Pharmacology, v. 258, n. 2, p. 151-165, 2012.

AXSON, J. L. et al. Rapid Kinetics of Size and pH-Dependent Dissolution and Aggregation of Silver Nanoparticles in Simulated Gastric Fluid. Journal of Physical Chemistry C, v. 119, n. 35, p. 20632-20641, 2015.

BERGIN, I. L. et al. Effects of particle size and coating on toxicologic parameters, fecal elimination kinetics and tissue distribution of acutely ingested silver nanoparticles in a mouse model, Nanotoxicology, v. 10, n. 3, p. 352-360, 2016.

BHUSHAN, B. Introduction to Nanotechnology. In: Springer Handbook of Nanotechnology. 1. ed. Berlin: Springer, Berlin, Heidelberg, 2017. p. 1-19.

BÖHMERT, L. et al. Analytically monitored digestion of silver nanoparticles and their toxicity on human intestinal cells. Nanotoxicology, v. 8, n. 6, p. 631-642, 2014.

BOLANDI, N. et al. Performance, intestinal microbial population, immune and physiological responses of broiler chickens to diet with different levels of silver nanoparticles coated on zeolite. Italian Journal of Animal Science, v. 20, n. 1, p. 497-504, 2021.

CHEN, N. et al. Toxicological effects of Caco-2 cells following short-term and long-term exposure to Ag nanoparticles. International Journal of Molecular Sciences, v. 17, n. 6, p. 1-17, 2016.

DONALDSON, K. et al. Nanotoxicology. Occupational and Environmental Medicine, v. 61, n. 9 , p. 727-728, 2004.

DOS SANTOS, C. A. et al. Silver Nanoparticles: Therapeutical Uses, Toxicity, and Safety Issues, Journal of Pharmaceutical Sciences, v. 103, n. 7, p. 1931-1944, 2014. 
GAILLET, S.; ROUANET, J. M. Silver nanoparticles: Their potential toxic effects after oral exposure and underlying mechanisms - A review. Food and Chemical Toxicology, v. 77, p. 58-63, 2015.

GEORGANTZOPOULOU, A. et al. Effects of silver nanoparticles and ions on a co-culture model for the gastrointestinal epithelium. Particle and Fibre Toxicology, v. 13, n. 1, p. 2-17, 2016.

GILLOIS, K. et al. Repeated exposure of Caco-2 versus Caco-2/HT29-MTX intestinal cell models to (nano) silver in vitro: Comparison of two commercially available colloidal silver products, Science of The Total Environment, v. 754, p. 1-55, 2021.

GIORIA, S. et al. Proteomics study of silver nanoparticles on Caco-2 cells. Toxicology in Vitro, v. 50, p. 347-372, 2018.

GOKULAN, K. et al. Human Intestinal Tissue Explant Exposure to Silver Nanoparticles Reveals Sex Dependent Alterations in Inflammatory Responses and Epithelial Cell Permeability, International Journal of Molecular Sciences, v. 22, n. 1, p. 1-15, 2020.

HENDRICKSON, O. D. et al. Toxicity of nanosilver in intragastric studies: Biodistribution and metabolic effects. Toxicology Letters, v. 241, p. 184-192, 2016.

JAMKHANDE, P. G. et al. Metal nanoparticles synthesis: An overview on methods of preparation, advantages and disadvantages, and applications. Journal of Drug Delivery Science and Technology, v. 53, p. 101-174, 2019.

JAVUREK, A. B. et al. Gut dysbiosis and neurobehavioral alterations in rats exposed to silver nanoparticles. Scientific Reports, v. 7, n. 1, p. 1-15, 2017.

JIMENO-ROMERO, A. et al. Digestive cell lysosomes as main targets for Ag accumulation and toxicity in marine mussels, Mytilus galloprovincialis, exposed to maltose-stabilised Ag nanoparticles of different sizes. Nanotoxicology, v. 11, n. 2, p. 168-183, 2017.

KAKAKHEL, M. A. et al. Long-term exposure to high-concentration silver nanoparticles induced toxicity, fatality, bioaccumulation, and histological alteration in fsh (Cyprinus carpio). Environmental Sciences Europe, v. 33, p. 14-24, 2021. 
KRUG, H. F.; WICK, P. Nanotoxicology: An interdisciplinary challenge. Angewandte Chemie International Edition, v. 50, n. 6, p. 1260-1278, 2011.

LALOUX, L. et al. The Food Matrix and the Gastrointestinal Fluids Alter the Features of Silver Nanoparticles. Small, v. 16, n. 21, p. 1-11, 2020.

LIU, Y.; WORKALEMAHU, B.; JIANG, X. The Effects of Physicochemical Properties of Nanomaterials on Their Cellular Uptake In Vitro and In Vivo. Small, v. 13, n. 43, p. 1-13, 2017.

MARTIROSYAN, A.; BAZES, A.; SCHNEIDER, Y. J. In vitro toxicity assessment of silver nanoparticles in the presence of phenolic compounds-preventive agents against the harmful effect? Nanotoxicology, v. 8, n. 5, p. 573-582, 2014.

NI, B.; SHI, Y.; WANG, X. The Sub-Nanometer Scale as a New Focus in Nanoscience. Advanced Materials, v. 30, n. 43, p. 1-24, 2018.

OBERDÖRSTER, G.; OBERDÖRSTER, E.; OBERDÖRSTER, J. Nanotoxicology: An emerging discipline evolving from studies of ultrafine particles. Environmental Health Perspectives, v. 113, n. 7, p. 823-839, 2005.

ORR, S. E. et al. Alteration in the mRNA expression of genes associated with gastrointestinal permeability and ileal TNF - $\alpha$ secretion due to the exposure of silver nanoparticles in Sprague Dawley rats. Journal of Nanobiotechnology, v. 17, n. 63, p. 1-10, 2019.

PECORARO, R. et al. Evaluation of chronic nanosilver toxicity to adult zebrafish. Frontiers in Physiology, v. 8, p. 1-9, 2017.

PINĎÁKOVÁ, L. et al. Behaviour of silver nanoparticles in simulated saliva and gastrointestinal fluids. International Journal of Pharmaceutics, v. 527, n. 1-2, p. 12-20, 2017.

SAHU, S. C. et al. Comparative genotoxicity of nanosilver in human liver HepG2 and colon Caco2 cells evaluated by a flow cytometric in vitro micronucleus assay. Journal Applied Toxicology, v. 34, p. 1226-1234, 2014. 
SAMBALE, F. et al. Investigations of the Toxic Effect of Silver Nanoparticles on Mammalian Cell Lines. Journal of Nanomaterials, vol. 2015, Article ID 136765, 9 pages, 2015. Disponível em: https://bit.ly/3HLq2QZ. Acesso em: 25 abr 2021.

SIDDIQI, K. S; HUSEN, A; RAO, R. A. K., A review on biosynthesis of silver nanoparticles and their biocidal properties, Journal of Nanobiotechnology, v. 16, n. 1, p. 14-42, 2018.

SOLOMON, S. D. et al. Synthesis and study of silver nanoparticles. Journal of Chemical Education, v. 84, n. 2, p. 322-325, 2007.

SRINONATE, A. et al. Acute Toxicity Study of Nanosilver Particles in Tilapia (Oreochromis niloticus): Pathological Changes, Particle Bioaccumulation and Metallothionien Protein Expression. Journal Medicina Veterinaria, v.45, p.81-89, 2015.

TRIPATHI, D. K., TRIPATHI, A., SHWETA, Uptake, Accumulation and Toxicity of Silver Nanoparticle in Autotrophic Plants, and Heterotrophic Microbes: A Concentric Review. Frontiers Microbiology, v. 8, p. 1-16, 2017.

VAN DER ZANDE, M. et al. Different responses of Caco-2 and MCF-7 cells to silver nanoparticles are based on highly similar mechanisms of action. Nanotoxicology, v.10, p. 1431-1441, 2016.

WILDING, L. A. et al. Repeated dose (28 day) administration of silver nanoparticles of varied size and coating does not significantly alter the indigenous murine gut microbiome. Nanotoxicology, v. 10, n. 5, p. 513-520, 2016.

WILLIAMS, K. et al. Effects of subchronic exposure of silver nanoparticles on intestinal microbiota and gut-associated immune responses in the ileum of Sprague-Dawley rats. Nanotoxicology, v. 9, n. 3, p. 279-289, 2015.

XIAO, B. et al. Bioaccumulation kinetics and tissue distribution of silver nanoparticles in zebrafish: The mechanisms and influence of natural organic matter. Ecotoxicology and Environmental Safety, v. 194, p. 1-7, 2020. 
YUN, J. et al. Comparative toxicity of silicon dioxide, silver and iron oxide nanoparticles after repeated oral administration to rats. Journal Applied Toxicology. v.35, p.681-693, 2015.

ZHANG, X. et al, Silver Nanoparticles: Synthesis, Characterization, Properties, Applications, and Therapeutic Approaches, International Journal of Molecular Sciences, v. 17, n. 9, p. 1534-1568, 2016. 